\title{
INNOVATIONS IN EDUCATION
}

\section{A Framework for Developing, Implementing, and Evaluating a Cancer Survivorship Curriculum for Medical Students}

\author{
Sebastian Uijtdehaage, $P h D^{7}$, Karen E. Hauer, $M D^{2}$, Margaret Stuber, $M D^{3}$, \\ Shobita Rajagopalan, MD", Vay L. Go, MD', and LuAnn Wilkerson, EdD ${ }^{7}$
}

${ }^{1}$ Center for Education Development and Research, David Geffen School of Medicine, UCLA, 60-051 Center for the Health Sciences, Los Angeles, CA, USA; ${ }^{2}$ Department of Medicine, Division of Hospital Medicine, University of California, San Francisco, San Francisco, CA, USA; ${ }^{3}$ Department of Psychiatry, Division of Child and Adolescent Psychiatry, David Geffen School of Medicine, UCLA, Los Angeles, CA, USA; ${ }^{4}$ Department of Medicine, Charles Drew University of Medicine and Science and David Geffen School of Medicine, UCLA, Los Angeles, CA, USA; ${ }^{5}$ Department of Medicine, Center for Excellence in Pancreatic Diseases, David Geffen School of Medicine, Los Angeles, USA.

BACKGROUND: Cancer survivorship care is not adequately addressed in current medical school curricula.

OBJECTIVES: To develop, implement, and evaluate a modular cancer survivorship curriculum that is portable to other educational settings and is designed to provide medical students with a foundation of knowledge, attitudes, and skills related to care for cancer survivors.

PROGRAM DESCRIPTION: An expert consensus panel developed a set of learning objectives related to cancer survivorship to guide the development of educational modules, such as computer-based self-instructional modules, problem-based learning cases, videos, and clinical exercises. Course and clerkship chairs were directly involved in the development and implementation of the modules.

EVALUATION: A cohort study with a historical control group demonstrated that fourth-year medical students increased their knowledge in survivorship issues and their self-reported level of comfort in care activities compared to similar students who did not receive the survivorship curriculum.

CONCLUSIONS: Our framework resulted in a cancer survivorship curriculum that was implemented in a modular manner across the medical curriculum that improved learning and that is potentially portable to other educational settings.

KEY WORDS: cancer survivorship; medical education.

J Gen Intern Med 24(Suppl 2):491-4

DOI: $10.1007 / \mathrm{s} 11606-009-1024-7$

(C) Society of General Internal Medicine 2009

\section{INTRODUCTION}

Thanks to recent advances in cancer screening, treatment, and prevention of recurrent malignancies, most cancer patients today can be expected to survive more than 5 years from the point of diagnosis. The overall 5-year relative survival rate now

Electronic supplementary material The online version of this article (doi:10.1007/s11606-009-1024-7) contains supplementary material, which is available to authorized users. exceeds 65 percent $^{1}$. Emerging therapeutic interventions such as personalized genomic therapy ${ }^{2}$ are likely to improve longterm outcomes for cancer survivors even more. General internists and family practitioners, by far the largest group of providers of survivorship care ${ }^{3}$, are encountering long-term cancer survivors in increasing numbers. However, they are not necessarily prepared to recognize the unique and life-long needs of these patients related to their previous cancer diagnosis and treatment ${ }^{4}$.

While medical schools have traditionally focused on the diagnosis and treatment of cancer, and more recently on its prevention ${ }^{5,6}$, curricula focusing on cancer survivorship are still rare $^{3}$. Consequently, trainees may feel more prepared to address acute manifestations of oncologic disease than to care for more stable patients with a history of cancer ${ }^{7}$. Cancer survivors have now joined the group of patients with other chronic diseases who are generally underrepresented in medical school curricula ${ }^{8}$, and towards whom students' attitudes decline during training ${ }^{9}$. A successful educational framework for developing a survivorship curriculum is bound to be complex as it involves multidisciplinary teams of specialists, primary care providers, and, ideally, longitudinal experience with patients.

\section{AIM}

In this paper we describe a framework for the development, implementation, evaluation, and dissemination of a curriculum that is portable to other educational settings and is designed to provide medical students with a foundation of knowledge, attitudes, and skills related to cancer survivorship.

\section{PROGRAM DESCRIPTION}

During the last 5 years (from 2003 through 2008), the David Geffen School of Medicine at UCLA, the University of California, San Francisco School of Medicine, and the Charles Drew University of Medicine and Science (CDU) have collaboratively developed a 4-year, integrated curriculum in cancer survivorship with support of an NCI R25 grant. Development of this curriculum occurred in several phases: (1) identification of curriculum objectives; (2) development of educational interventions and integration into the existing curriculum; (3) 
evaluation and dissemination. The curriculum focused on common cancers with increasing survival rates: breast, colorectal, prostate, and gynecological cancers along with childhood cancers such as leukemia.

1. Identification of curriculum objectives

A 15-member multidisciplinary expert consensus panel with representation from the three participating institutions was charged with developing a set of curriculum objectives for the care of patients with cancer as a chronic disease ${ }^{10}$. Faculty members from various oncology specialties, primary care, and curriculum design specialists met at each of the institutions and created comprehensive lists of knowledge, attitudes, and skills related to survivorship care that medical students should demonstrate upon graduation. Next, using a modified Delphi process, panel members prioritized all items on the collated list, resulting in a final set of 17 objectives. Knowledge objectives pertained to epidemiology of survival, survival rates, psychosocial effects of cancer, and long-term effects of treatment. Skill objectives included, but were not limited to, provide recommendations for secondary prevention of cancer, prescribe appropriate pain medication, give bad news about a second malignancy, and locate current cancer information. The complete list of curriculum objectives has appeared in the
Institute of Medicine report, From Cancer Patient to Cancer Survivors: Lost in Translation ${ }^{3}$ and elsewhere ${ }^{11}$.

2. Development and implementation of educational interventions

Curriculum objectives guided the development of educational interventions addressing specific cancers ${ }^{12}$. A modular approach was taken as opposed to developing a new course or clerkship. That is, smaller stand-alone units that supported a limited number of objectives were created to allow integration into existing courses and clerkships. The resulting set of approximately 30 educational modules used a variety of educational strategies (see Table 1 for a complete overview). The following is a representative sample:

(1) The case of Mrs. Hernandez: a video problem-based learning (PBL) case

This video-based PBL case features Mrs. Hernandez, a 56year-old immigrant from Mexico, who presents to an urgent care physician with chest pain and cough. She is initially diagnosed with pneumonia. Her symptoms progress, and she is subsequently diagnosed with stage IIIA adenocarcinoma of the lung, which is treated with chemotherapy and radiother-

Table 1. Survivorship Curricular Materials Developed Under NCI 096975

\begin{tabular}{|c|c|c|}
\hline Topic & $\begin{array}{l}\text { Implementation course and student level } \\
\text { (MS1-MS4) }\end{array}$ & Format \\
\hline Stress management exercise & Behavioral science course, MS 1 & Diary with self-reflection and group discussion \\
\hline Cooking for health & Elective, MS 1 and 2 & Workshop \\
\hline CAM for stress relief & Neuroscience course, MS 1 & Workshop \\
\hline Giving bad news & Behavioral science course, MS 2 & Standardized patient exercise \\
\hline Tobacco cessation counseling & Integrated cancer course, MS 1 & Standardized patient exercise \\
\hline Breast cancer follow-up & Behavioral science course, MS 1, 2, and 3 & Standardized patient exercise \\
\hline Dietary counseling and adherence & Behavioral science course, MS 1 & Standardized patient exercise and $\mathrm{PBL}^{* *}$ case \\
\hline Breast-cancer survivor case & Psychopathology course, MS 1 & OSCE* \\
\hline Advanced directives case & Internal medicine clerkship, MS 3 & OSCE \\
\hline Smoking cessation case & Internal medicine clerkship, MS 3 & OSCE \\
\hline Colon cancer case & Internal medicine clerkship, MS 3 & OSCE \\
\hline Cancer survivor write-up template & Internal medicine clerkship, MS 3 & Required case report \\
\hline Cancer survivorship statistics & Internal medicine clerkship, MS 3 & Lecture slides \\
\hline Cancer survivor patient communication & Internal medicine clerkship, MS 3 & Lecture slides \\
\hline Breast cancer and survivor issues & Internal medicine clerkship, MS 3 & Lecture slides \\
\hline Colorectal cancer and survivor issues & Internal medicine clerkship, MS 3 & Lecture slides \\
\hline Prostate cancer and survivor issues & Internal medicine clerkship, MS 3 & Lecture slides \\
\hline IOM: from cancer patient to cancer survivor & Elective, MS 1 and 2 & Video \\
\hline Childhood cancer survivor panel & Behavioral science course, MS 1 & Video and panel \\
\hline Hodgkin's survivor: late effects & Behavioral science course, MS 1 & Video case for group discussion \\
\hline Childhood lymphoma survivor & Behavioral science course, MS 1 & Video case for group discussion \\
\hline Cancer information resources & $\begin{array}{l}\text { Integrated basic/clinical science course, } \\
\text { MS } 1 \text { and } 2\end{array}$ & Computer laboratory workshop \\
\hline $\begin{array}{l}\text { Uterine cancer, initial diagnosis, } \\
\text { and treatment, Part A, B }\end{array}$ & Obstetrics/gynecology clerkship, MS 3 & Computer-based self-instructional module \\
\hline Prostate cancer and survivorship & Surgery clerkship, MS 3 & Computer-based self-instructional module \\
\hline Colon cancer survivorship & Surgery clerkship, MS 3 & Computer-based self-instructional module \\
\hline Breast, colon, and prostate cancer survivors & Integrated cancer course, MS 2 & Computer-based self-instructional module \\
\hline Lung cancer and survivorship & Integrated cancer course, MS 2 & Computer-based self-instructional module \\
\hline Discussing advanced directives & Behavioral science course, MS 1 & PBL case \\
\hline Colon cancer diagnosis, management, and prognosis & Integrated basic/clinical science course, MS 2 & PBL case \\
\hline Brain cancer survival & Integrated cancer course, MS2 & PBL case with video \\
\hline Lung cancer recurrence & Integrated cancer course, MS 2 & PBL case with video \\
\hline Jonna's Body, Please Hold & Elective, MS 1 and 2 & Theater performance \\
\hline
\end{tabular}

*OSCE $=$ Objective structured clinical examination, $\mathrm{PBL}=$ problem-based learning 
apy. The case ends with a 6-month follow-up visit when the patient is in remission, and the physician must discuss her concerns about recurrence of her cancer and her health beliefs. Students learn to describe the pathophysiology of lung cancer, the relationship between staging and prognosis, and the factors affecting the patient's quality of life after treatment

(2) Surviving endometrial cancer: a computer-based selfstudy module

In this module, students encounter a 64-year-old woman who visits her primary care physician after being treated for Stage 2A endometrial cancer. Over the subsequent 20 months, she returns to the physician several times for a variety of complaints, including hair loss, swollen feet, weight loss, and concerns about recurrence of the cancer. At her 1-year checkup with the oncologist, she is diagnosed with a paraaortic lymph node indicative of a localized relapse. With each visit, the student is required to make diagnostic, treatment, and counseling decisions.

(3) The human side of survivorship: panel and theater presentation of cancer survivors

First-year medical students have an opportunity to see the human side of survivorship issues through a 90-min panel presentation. The panel occurs during a week in which the students analyze skin biopsies from patients with malignant melanoma. Three or four cancer survivors tell their stories, starting with how they were diagnosed and treated. They then discuss the impact of cancer and treatment on their relationships, jobs, and self-perception. They describe how they coped with interacting with multidisciplinary teams, their use of complementary or alternative medicine, and any insurance issues they encountered. Students have reviewed this panel presentation very positively and are grateful for this glimpse into the cancer experience. In addition, students have a chance to see a one-woman show on the experience of being a cancer survivor (Jonna's Body ${ }^{13}$ ). Dramatic story telling and humor create emotional links for students to the survivorship experience.

\section{(4) Cancer survivorship write-up exercise}

In this exercise, students identify a cancer survivor among the patients for whom they are caring during their inpatient internal medicine clerkship. The patient may or may not have been hospitalized because of a cancer-related problem. Guided by a template, they conduct and then write up a detailed cancer history of the patient, including details of cancer treatment and follow-up. In addition to the usual history and physical examination findings, students are prompted to address quality of life issues, pain control, advance directives, and secondary screening. This write-up exercise is designed to prompt students to identify cancer survivors during their clerkship, increase their awareness of survivorship issues, and to conduct a detailed cancer history.

Having a pre-clerkship curriculum that includes PBL, innovative laboratory sessions, and a longitudinal "Doctoring" course facilitated the insertion of the modules. PBL survivor cases could be offered to course chairs to replace existing cases with similar learning goals but lacking a survivor focus. The "Doctoring" course chairs helped develop and implement the majority of skill-based modules in their course including the panel of cancer survivors, behavior change counseling, and advanced directives. The same implementation strategy worked for the clerkships as well. By involving clerkship chairs and site directors at UCSF, CDU, and UCLA in curriculum development, knowledge-oriented modules could be inserted in clerkships in internal medicine, surgery, and obstetrics/gynecology. A limitation to this approach is the need to negotiate for the needed curricular time for the integration of these new materials.

\section{PROGRAM EVALUATION}

Students evaluated the usefulness of each curricular module and provided suggestions for improvement. In addition, we used a cohort study with a historical control group to assess the effect of the curriculum on students' knowledge of and experience with cancer survivorship. In 2004, we developed an instrument to measure students' fund of knowledge on survivorship issues (25 multiple choice questions) and their self-rated comfort levels in survivorship care (nine items rated on a five-point Likert scale) ${ }^{14}$. This survey instrument is available online. Questionnaire items covered the five cancer types addressed in the curriculum and yielded acceptable reliability levels (Chronbach's alpha $=0.67$ ). We determined discriminant validity with a group of oncology fellows, who performed significantly better than medical students. In addition, we asked students to estimate how many times during medical school they had observed someone else caring for survivors, received direct instruction or practiced specific skills related to cancer survivors. Prior to implementing the new curriculum, we administered the instrument to a historical control group in $2005^{15,16}$ and in subsequent years as the curriculum was phased in.

The historical control group consisted of 211 fourth-year medical students at the three participating programs (Class of 2006). These students had not experienced a dedicated cancer survivorship curriculum. The intervention group consisted of 195 students in the Class of 2007 who had been exposed to a different combination of modules at each institution, 10 modules at UCSF, 19 at UCLA, and 20 at CDU.

The control group demonstrated the serious shortcomings of the educational status quo ${ }^{7}$. They lacked knowledge in key survivorship issues, such as long-term consequences of cancer treatments. Furthermore, while all students reported some contact with cancer survivors during their clerkships, less then half received direct instruction or were afforded the opportunity to practice critical components of survivorship care.

Educational outcomes gradually improved as the cancer survivorship modules were introduced into the curriculum ${ }^{17}$. Compared to the historical controls, the intervention groups at UCLA and CDU improved their scores on average by about $43 \%$ ( $\mathrm{p}<0.001$ ). Students at UCSF, where fewer modules were implemented, did not demonstrate such a knowledge gain. Students at all institutions, however, reported to be more comfortable in several care activities $(\mathrm{p}<0.05)$, including working in a specialty team and identifying patients with high cancer recurrence risks. Students also reported having encountered more cancer survivors compared to the control group. Whereas in previous years cancer survivors may have rarely been identified as such, the emphasis of the new 
curriculum on taking a cancer history may have raised the awareness among medical students of cancer survivors presenting in clinics and on ward rotations.

\section{DISSEMINATION}

Most of the educational modules of our cancer survivorship curriculum are stand-alone and, thus, can be easily shared with other institutions. Many of them have been showcased at the annual meeting of the American Association for Cancer Education $^{18}$ and at the Innovations in Medical Education Exhibits during the annual meeting of the Association of American Medical Colleges $^{19}$. We also created a dedicated website ${ }^{20}$ where many of the materials can be downloaded or requested free of charge.

\section{DISCUSSION}

Appropriate training of future physicians is needed, regardless of specialty, to address the unique needs of the rapidly increasing population of cancer survivors. New models of delivering survivorship care are still being proposed ${ }^{21}$, and consequently, training across the continuum will need to be adapted continuously. Our modular approach facilitated the implementation and integration of our interventions across the 4 years of medical school at diverse institutions, provided maximum flexibility to incorporate emerging treatment options, and yielded portable products that were easily disseminated to other institutions. The development of curriculum objectives by an expert consensus panel drove the development of specific interventions. Having faculty members who could champion these objectives with their colleagues who serve as course and clerkship chairs was an essential component for success.

The gradual introduction of our curriculum was associated with an improvement in knowledge and comfort levels related to survivorship care and raised students' awareness of survivors. Our evaluation strategy, however, lacked objective evaluation of students' skills either by patients or trained observers. Thus, the effect of our curriculum on actual survivorship care (beyond knowledge, attitudes, and experience) was not determined.

In sum, our framework resulted in a cancer survivorship curriculum that was flexibly implemented at multiple sites using a modular approach and strategic involvement of curricular leaders. Students demonstrated improved learning and more survivorship experience over controls. The resulting modules are adaptable for a variety of health profession students and can be integrated into existing courses and clerkships with appropriate negotiation.

Acknowledgements: This research study was made possible by a grant from the National Cancer Institute, R25 CA096975, 20022007, (PI: LuAnn Wilkerson). The authors wish to acknowledge the contributions of Patricia Ganz, MD, to the initiation of this project.

Conflict of Interest: None disclosed.
Corresponding Author: Sebastian Uijtdehaage, $\mathrm{PhD}$, Center for Education Development and Research, David Geffen School of Medicine, UCLA, 60-051 Center for the Health Sciences, Box 951722, Los Angeles, CA 90095, USA (e-mail: bas@mednet.ucla.edu).

\section{REFERENCES}

1. Ries LAG, Melbert D, Krapcho $\mathbf{M}$, Stinchcomb DG, Howlader N, Horner MJ, Mariotto A, Miller BA, Feuer EJ, Altekruse SF, Lewis DR, Clegg L, Eisner MP, Reichman M, Edwards BK (eds). SEER Cancer Statistics Review, 1975-2005, National Cancer Institute. Bethesda, MD, http://seer.cancer.gov/csr/1975_2005/. [Assessed on April 2, 2009]

2. Garman KS, Nevins JR, Potti A. Genomic strategies for personalized cancer therapy. Hum Mol Genet. 2007; 16Spec No. 2: R226-32.

3. Institute of Medicine. From Cancer Patient to Cancer Survivor: Lost in Translation, Survivorship Report. Washington, DC, National Academy Press, 2006.

4. Rowland JH, Hewitt M, Ganz PA. Cancer survivorship: A new challenge in delivering quality care. J Clin Oncol. 2006; 2432: 5101-4.

5. Hauer KE, Wilkerson $\mathbf{L}$, Teherani A. The relationship between medical students' knowledge, confidence, experience, and skills related to colorectal cancer screening. J Cancer Educ. 2008; 234: 209-13.

6. Lee M, Wilkerson L, Harrity S, Hodgson CS. Differences in cancer prevention knowledge and experience among medical students at three institutions over time. J Cancer Educ. 2006; 214: 223-9.

7. Uijtdehaage $\mathbf{S}$, Hauer $\mathbf{K E}$, et al. Preparedness for caring of cancer survivors: a multi-institutional study of medical students and oncology fellows. J Cancer Educ. 2009; 241: 28-32.

8. Pham HH, Simonson L, Elnicki DM, Fried LP, Goroll AH, Bass EB. Training US medical students to care for the chronically ill. Acad Med. 2004; 791: 32-40.

9. Arenson CA, Rattner S, Borden C, Collins L, Fields SK, Gavin E, Veloski JJ. Cross-sectional assessment of medical and nursing students' attitudes toward chronic illness at matriculation and graduation. Acad Med. 2008; 8310 Suppl: S93-6

10. Stuber $\mathbf{M}$, Guiton $\mathbf{G}$, Wilkerson $\mathbf{L}$. Cancer as a chronic illness: Competencies for a curriculum for medical students. J Cancer Educ. 2003; 183 Suppl: 23.

11. Ferrell BR, Winn R. Medical and nursing education and training opportunities to improve survivorship care. J Clin Oncol. 2006; 2432: 5142-8.

12. Stuber M, Wilkerson L, Go VL. Integration of cancer survivorship coursework into first year medical school curriculum. J Cancer Educ. 2004; 193, Suppl: 35.

13. Jonna Tomases. Jonna's body, please hold. http://www.jonnasbody. com. [Accessed on April 2, 2009]

14. Wilkerson L, Go VL, Stuber M, Uijtdehaage S. Developing instruments to measure knowledge and experience related to cancer survivorship. J Cancer Educ. 2005; 203, Suppl: 16.

15. Uijtdehaage S, Hauer K, Wilkerson L, Stuber M, Go VL, Rajagopalan S. Cancer survivorship: What do medical students know? J Cancer Educ. 2006; 212, Suppl: 37.

16. Uijtdehaage S, Wilkerson L, Stuber M, Go VL, Hauer K, Rajagopalan S. Cancer survivorship: What do medical students experience? J Cancer Educ. 2006; 212, Suppl: 17

17. Uijtdehaage $\mathbf{S}$, Hauer $\mathbf{K}$, Rajagopalan $\mathbf{S}$, Wilkerson $\mathbf{L}$. Improving knowledge of and experience with cancer survivors: Effects of a dedicated curriculum. J Cancer Educ. 2007; 224, Suppl: 72.

18. American Association for Cancer Education. www.aaceonline.com. [Accessed on April 2, 2009]

19. Association of American Medical Colleges. Innovations In Medical Education Exhibits. http://www.aamc.org/members/gea/. [Assessed on April 2, 2009].

20. David Geffen School of Medicine, UCLA. UCLA Cancer Survivorship. http://www.medsch.ucla.edu/cancersurvivorship/. [Accessed on April 2, 2009].

21. Oeffinger KC, McCabe MS. Models for delivering survivorship care. J Clin Oncol. 2006; 2432: 5117-24. 